\title{
Pain and Functional Limitations in Patients with Fibromyalgia
}

\author{
Shahid Ishaq ${ }^{1}$, Umer Maqsood ${ }^{2}$, Hafiz Shehraz Arshad ${ }^{3}$ \\ ${ }^{1}$ Azra Naheed Medical College, Department of Physical Therapy, Main Raiwind Road,, Lahore \\ ${ }^{2}$ Assistant Professor, Azra Naheed Medical College, Department of Physical Therapy, Main Raiwind Road,, Lahore \\ ${ }^{3}$ Assistant Professor, Azra Naheed Medical College, Department of Physical Therapy, Main Raiwind Road,, Lahore
}

\begin{abstract}
Fibromyalgia is characterized by chronic widespread pain (CWP) and Functional limitation. A survey conducted among 40 patients with fibromyalgia (FMS) within three month. Frequency of FMS was higher among females $85 \%$ and males $15 \%$. In conclusion, FMS affected most commonly the age group above 30 years with moderate level of CWP and impact of pain on quality of life. Patients with FMS could occasionally performed house hold activities including ADLs and IADLs with reduced level of physical performance and had moderate to severe level of symptom severity. The severe symptoms among the recruited persons were depression and chronic wide spread pain (CWP)
\end{abstract}

Keywords: Fibromyalgia syndrome (FMS), Activities of daily living (ADLs), Physical performance (PF), Quality of Life (QoL), chronic widespread pain (CWP)

\section{Introduction}

American College of Rheumatology (ACR) proposed the criteria for classification of Fibromyalgia syndrome (FMS). The patient presented with 11 out of 18 tender points on different surface areas of body. (1,2). Fibromyalgia is a second common diagnosed syndrome in Rheumatology centers that affects commonly the middle aged females. Researcher believes that physiological and psychological stress are most triggering and predisposing factor of FMS(3).

Patients of the FMS syndrome have many cognitive disorders that affect the quality of Life (QoL) and activities of daily livings. Patients with FMS develop the chronic fatigue syndrome (CFS), enhance the cognitive complaints and worsen the physical impairment. Intensity of pain becomes worse with physical activity, psychological and physiological stress. (4).

It is considered as medical unexplained and globally functional somatization disorder. Arthralgias, myalgias, fatigue, headache, sleep disorders and many other somatic disorders are present in patients with FMS.(5). CWP is major and prevalent symptom of patients suffered with FMS. It also affects the work related activities, job, social relations and also leads many other complications.(6).

Physical or emotional trauma contributes as major disability causing factor that aggravates the symptoms and Physical/functional disability including house hold activities or performing ADLs and IADLs in more horrible way rather than emotional trauma.(7)

Fibromyalgia affects the 3 percent of the general population (1.5 percent men and 5 percent women). Patient with FMS experience the additional symptoms such as tenderness stiffness, fatigue and pain in joint ligaments and tendons. (8).Prevalence of Fibromyalgia in young adult is $2 \%$.it varies in between $0.66 \%$ to $10.5 \%$. The $75 \%$ population of
FMS remains undiagnosed.(9) A complex mechanism involved to impair the function and decrease the quality of life .The central nervous system undergoes many changes and affect the psychomotor function (10) It is very challenging disorder for clinician because of variety of symptoms such as pain, severity of depression, sleep disturbance, mood, physical and cognitive impairment. Complexity in symptoms is because of abnormal between CNS and peripheral nervous system (PNS).(11). Physicians consider the CWP, fatigue and functional disability as main criteria in the evaluation of fibromyalgia severity.(12-14).

Patients with FMS represent an event on their degree of spirit and their steady of perceived impairment seems to be influenced by their mental health. Psychological stress affects the life more rather than other conditions.(15)

Patients with fibromyalgia syndrome have a significant relationship between perceived stress, functionality and depression except pain but pain interfere in the quality of life.(10) . In conclusion, we can say that, psychological comorbidities especially depression and mood decreases the HRQoL(16). Patients with FMS have more psychological stress as compared to patients with other pain syndrome. It has substantial effect on level of physical activity.(17)

\subsection{Rationale}

This study had greater importance because we determined the pain and functional limitation that will help the caregiver to improve the quality of life of patients by reducing pain and functional limitation.

\subsection{Operational definition}

Fibromyalgia is a syndrome that mainly affects all the systems and regions of the body as well as it also cause the functional limitation that is evaluated and examined by Fibromyalgia Impact questionnaire (FIQ) it will measure fibromyalgia (FM) patient status, progress and outcomes. 


\section{International Journal of Science and Research (IJSR) \\ ISSN (Online): 2319-7064}

Index Copernicus Value (2013): 6.14 | Impact Factor (2015): 6.391

Pain is the major factor that affects the patients with fibromyalgia that is analyzed with Brief pain inventory scale BPI. (18)

\subsection{Objectives of Study}

To determine the pain (Pain severity and impact pain on quality of life) and functional limitation (physical impairment including ADLs/IADLs and symptom severity score) in patients with FMS.

\section{Methodology}

\subsection{Design of study}

Case Series study design was used in this research study. The individual experienced the FMS (adverse health event) were examined by Questionnaire and rating scale form.

\subsection{Study Duration}

This Research study was completed in duration of Four months after approval from research committee Azra Naheed Medical College (ANMC).

\subsection{Settings}

The sample was collected from the following settings of Lahore Pakistan..

- Ifat Anwer Medical and Acupuncture complex Lahore

- Mid city Hospital, Lahore

- Rubab Hospital, Lahore

- Sharif Medical city trust and teaching hospital

- Iqbal Mehmooda Trust Hospital, Lahore

\subsection{Sample Size}

The Sample size of this research was 40 patients with fibromyalgia syndrome. The sample size was calculated by the software Rao-soft sample size calculator according to following formula.

$\mathrm{x}=\mathrm{Z}(\mathrm{c} / 100)^{2} \mathrm{r}(100-\mathrm{r})$

$\mathrm{n}=\mathrm{Nx} /\left((\mathrm{N}-1) \mathrm{E}^{2}+\mathrm{x}\right)$

$\mathrm{E}=\operatorname{Sqrt}\left[{ }^{(\mathrm{N}-\mathrm{n}) \mathrm{x} / \mathrm{n}(\mathrm{N}-\mathrm{1})]}\right.$

$\mathrm{N}$ used for population Size, E for margin error, $\mathrm{Z}(\mathrm{c} / 100)$ is value for confidence level.

This research study can tolerate only a 5\% margin of error with 98\% confidence level. 40 diagnosed patients with fibromyalgia syndrome are voluntarily available on above mention settings. We are expecting 90\% response rate.

\subsection{Technique of Sample collection}

Non probability convenience sampling technique was used for sample taking. The patients with FMS were chosen according to ease. Non probability technique was chosen because the researcher was bounded to time, work force, and convenience.

\subsection{Inclusion criteria}

- Patients with FMS age between 15 to 50 years.

- Patients diagnosed with FMS not more than 10 month according to the American College of Rheumatology 2010 proposed criteria for fibromyalgia syndrome.

\subsection{Exclusion criteria}

- The patient refused to take part.

- Patients with any other chronic pain disease such as sciatica or other regional pain syndrome were excluded.

- Patients diagnosed with skin disease, open wound, rheumatic disease and under psychological treatment from 2 to 3 year were not included in the sample of this study.

\subsection{Tools of data collection}

Brief pain inventory (BPI) scale was used to measure pain. This scale used 0-10 numerical for measuring the severity of pain and pain interference in daily functioning. (18). Functional impairments were measured with Fibromyalgia impact questionnaire (FIQ). A 10 item tool measured the severity of symptoms and functional impairment that affects the daily life. It also measures the interference of pain in work, illness leaves and feeling of wellness in previous week. (18). (19).

\subsection{Questionnaire}

A self reported form was used to obtain information regarding name, sex, age, and consent for eligibility. It conducted the information about the length of time since diagnosis of fibromyalgia, Psychiatric, Medical and Medicine history.

\subsection{Statistical procedures}

The data was analyzed by using IBM SPSS Statistics version 21, Mean and +_SD (Standard Deviation) will give for Brief Pain Inventory Scale (BPIS) and Fibromyalgia impact Questionnaire (FIQ) score. Frequency of female and male will be compared by using Frequency table. Descriptive statistics will be used to analyze data.

\section{Results}

Total $(n=40)$ patients were recruited on different above mentioned clinics with in time period of the month.

\subsection{Demographic Variables}

Table 1

\begin{tabular}{|c|c|c|c|}
\hline & & Frequency & Percent \\
\hline \multirow{2}{*}{ Gender } & Male & 6 & 15 \\
\cline { 2 - 4 } & Female & 34 & 85 \\
\hline \multirow{2}{*}{ Age } & $15-30$ years & 17 & 42.5 \\
\cline { 2 - 4 } & 31-50years & 23 & 57.5 \\
\hline
\end{tabular}

The frequency of female patients was higher $85 \%$ and male $15 \%$. Most of the recruited patients were above age of 30 years $57.5 \%$ than patients, who were under 30 years $(42.5 \%)$. 


\section{International Journal of Science and Research (IJSR) ISSN (Online): 2319-7064 \\ Index Copernicus Value (2013): 6.14 | Impact Factor (2015): 6.391}

\subsection{Pain and Functional limitation Score}

The Descriptive statistic score of pain and functional Limitation is presented in the Table (2).

Table 2

\begin{tabular}{|c|c|}
\hline Variables & Mean \pm SD \\
\hline Pain Severity & $2.0188 \pm .41752$ \\
\hline Pain impact in QoL & $1.5214 \pm .46494$ \\
\hline ADLs \& IDLs or Physical Impairment & $1.9107 \pm .36329$ \\
\hline Symptoms Severity & $2.3964 \pm .32910$ \\
\hline Days of Feel Good & $1.8750 \pm .72280$ \\
\hline Missed Work & $2.6750 \pm 1.11832$ \\
\hline Pain Relief & $1.75 \pm .439$ \\
\hline
\end{tabular}

Pain severity score $(2.0188 \pm .41752)$ Mean \pm SD (Standard deviation) is measure by four variable (Worst pain, Least pain, Average pain and Current Pain) of BPI (short form) scale. The calculated score represents that, patients recruited for this research have moderate level of pain intensity/severity. The impact of pain on quality of life was measured 7 variables (general activity, walking ability, normal work, social relationship, enjoyment of life) of BPI (short form) by 0 - 10 rating scale. This $0-10$ rating scale of each variable measures the interference of pain during last 24 hours. Pain interference in QoL score(1.5214 \pm .46494) Mean \pm SD deducted that, Pain has average mild to moderate level of interference in QoL of patients with FMS. The pain relief score is $(1.75 \pm$.439) Mean \pm SD. This concludes patients receiving medication have moderate relief from severity of symptoms and CWP.

The eleven items of FIQ were used to measure the physical impairment/functional disability. These item are consists of household activities and physical functioning. The four step lickert type scale was used to measure the level of activity. Average physical impairment score $(1.9107 \pm$.36329) Mean \pm SD justified that, patients with FMS recruited as sample of this research study can occasionally perform the house hold activities and physical functioning (ADLs and IADLs). Symptoms severity score was measured by interpreting pain interference in work, pain severity, morning feel, stiffness, anxious and depression. The symptom severity score (2.3964 \pm .32910) Mean \pm SD demonstrated that, Patients have moderate to high severity of symptoms. Twelfth question of FIQ was inversely operated and reverse scoring had score $(1.8750 \pm .72280)$ Mean \pm SD. Days of missed work including house work had score $(2.6750 \pm 1.11832)$ Mean \pm SD.

\subsection{Symptoms Severity Score}

The Patients with FMS have moderate to severe symptoms severity score. All symptoms have closely resembled results.

Table 3

\begin{tabular}{|c|c|}
\hline Symptoms & Severity Score \\
\hline Symptom interfere & $1.95 \pm .504$ \\
\hline Pain intensity & $2.53 \pm .640$ \\
\hline Tiredness & $2.30 \pm .648$ \\
\hline Morning Feel & $2.23 \pm .680$ \\
\hline Stiffness & $2.45 \pm .504$ \\
\hline Tension or Anxious & $2.60 \pm .496$ \\
\hline Depression & $2.73 \pm .599$ \\
\hline
\end{tabular}

The above results have clear justification about the severity of symptoms. Depression was reported as most severe symptom (2.73 \pm .599$)$ among the patients of FMS. Patients with FMS experienced high intensity $(2.53 \pm .640)$ of pain

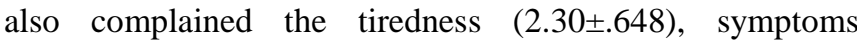
interference (1.95 \pm .504$)$, morning feel (2.23 \pm .680$)$, stiffness

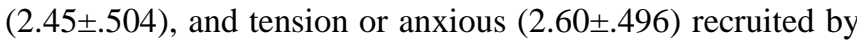
$0-10$ rating scale by dividing it into five categories $(0=$ no symptom, 1=mild symptom, $2=$ =moderate symptom, 3=severe symptom and 4=complete inference of symptom). Most of the patients recruited in different clinics of Lahore Pakistan have moderate to severe pain intensity, depression, tiredness, morning feel, stiffness and tension. So it is concluded that above mention symptoms have major influence as a complications in patient with FMS.

\section{Discussion}

Patient recruited for present study had moderate level of pain severity score with decreased physical performance. The pain intensity score of this study has close resemblance with study done by Bennett et al., Moderate to severe pain intensity significantly impaired the HRQoL. (20)

Fibromyalgia has negative effect on the quality of life, social relations and reduce the activities of daily living. Arnold et al, also concluded that fibromyalgia has negative impact on lives of Fibromyalgia patients. FMS syndrome badly affects the Social relations and occupational life. It leads the fatigue, sleep, cognitive impairment and functional disability (21)

Previous researches have justification for the prevalence of FMS syndrome is higher among female than male. The ratio is 9:1 respectively. Our study also proved that the $85 \%$ females with age between 31 year to 50 years are recruited with FMS in setting from data of this research is collected and only $15 \%$ men visited these clinics with FMS.

Fibromyalgia was characterized by functional impairment including impairment in physical functioning and occupational disability. It was characterized as social security disability. Our study also commenced it as a disease of social security disability. It affects the social interaction, relation with friends and relatives, and job. (22)

FMS is chronic pain syndrome characterized with functional and emotional impairment. The study $1^{\text {st }}$ time deducted that variety of physical and emotional impairment among the patients with FMS diverge in same age group.(23)

Fibromyalgia syndrome is characterized as chronic pain disorder with many other symptoms such as sleep disturbance, tenderness, morning feel, and affected quality of life, emotional and physical impairment. According to my knowledge, it is $1^{\text {st }}$ study done in Pakistan to determine the level of Pain (pain intensity/severity \& pain interference in quality of life) and Functional limitation (Physical impairment and symptom severity score). Symptom severity score was founded moderate to severe that negatively affect the physical functioning and household activities. A previous research study measured the perceived function in association with physical performance and concluded that, 


\section{International Journal of Science and Research (IJSR) ISSN (Online): 2319-7064 \\ Index Copernicus Value (2013): 6.14 | Impact Factor (2015): 6.391}

Pain and fatigue have more significant association and lead to one third of physical and functional variation.(24)

\section{Limitation of Study}

- The Patients with Fibromyalgia involved in this study belongs to Lahore Pakistan who are not true representation of Fibromyalgia patients across the world and not even the whole population of Pakistan. So it is concluded that, generalize limitation of study because the sample size is restricted to Lahore Pakistan.

- FMS is often undiagnosed in Pakistan. That's why the short sample size is not true representation the Patients of FMS across the Pakistan.

- This study was not described the exact personality of FMS patients, that's why the further researches are required to define the personality of FMS relation to psychological manifestation among the population of Pakistan.

\section{Conclusion}

The 40 patients with FMS recruited in different clinics of Lahore Pakistan within the duration of three month. Most of them were females (85\%) and men (15\%). Frequency of FMS was found higher (57\%) among people of age above 30 year as compared to under 30 years of age (42\%). The patients with FMS have pain severity score 2.0188 \pm .41752 which concludes that patients feel moderate pain and moderate pain impact $(1.5214 \pm .46494)$ on quality of life. Patients with FMS had physical impairment and moderate level of impairment founded in ADLs and IADLs

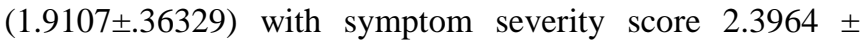
.32910. Symptom severity score is moderate to high with less days of feeling good 1.8750 \pm .7228 and with average 2-3 days missed work $2.6750 \pm 1.11832$ in a week. This syndrome negatively affected the quality of life and performance of daily living activities. It is characterized as the pain full disorder. Patients with moderate to higher symptom severity score could performed activities of daily living occasionally. Finally it is concluded that FMS has negative impact on quality of life and cause physical impairment in activities of daily livings.

\section{References}

[1] Arnold LM, Crofford LJ, Mease PJ, Burgess SM, Palmer SC, Abetz L, et al. Patient perspectives on the impact of fibromyalgia. Patient Educ Couns. 2008;73(1):114-20.

[2] Hsiao MY, Hung CY, Chang KV, Han D, Wang TG. Is Serum Hypovitaminosis D Associated with Chronic Widespread Pain Including Fibromyalgia? A Metaanalysis of Observational Studies. Pain Physician. 2015;18(5):E877-87.

[3] Gonzalez B, Baptista TM, Jaime C. Branco. Life History of Women with Fibromyalgia: Beyond the Illness. $2015 ; 20$.

[4] Schmaling KB, Betterton KL. Neurocognitive complaints and functional status among patients with chronic fatigue syndrome and fibromyalgia. Quality of Life Research. 2015:1-7.
[5] Borchers AT, Gershwin ME. Fibromyalgia: A Critical and Comprehensive Review. Clin Rev Allergy Immunol. 2015;49(2):100-51.

[6] Flodin P, Martinsen S, Lofgren M, Bileviciute-Ljungar I, Kosek E, Fransson P. Fibromyalgia is associated with decreased connectivity between pain- and sensorimotor brain areas. Brain Connect. 2014;4(8):587-94.

[7] Verbunt JA, Pernot DH, Smeets RJ. Disability and quality of life in patients with fibromyalgia. Health and Quality of Life Outcomes. 2008;6(1):1-8.

[8] Ellingson LD, Shields MR, Stegner AJ, Cook DB. Physical activity, sustained sedentary behavior, and pain modulation in women with fibromyalgia. The journal of pain : official journal of the American Pain Society. 2012;13(2):195-206. Epub 2012/01/17.

[9] Clauw DJ, Arnold LM, McCarberg BH. The Science of Fibromyalgia. Mayo Clinic Proceedings. 2011;86(9):907-11.

[10] Homann D, Stefanello JM, Goes SM, Breda CA, Paiva Edos S, Leite N. Stress perception and depressive symptoms: functionality and impact on the quality of life of women with fibromyalgia. Revista brasileira de reumatologia. 2012;52(3):319-30. Epub 2012/05/30.

[11] Sarzi-Puttini P, Atzeni F, Di Franco M, Buskila D, Alciati A, Giacomelli C, et al. Dysfunctional syndromes and fibromyalgia: a 2012 critical digest. Clin Exp Rheumatol. 2012;30(6 Suppl 74):143-51.

[12] Silverman S, Sadosky A, Evans C, Yeh Y, Alvir JM, Zlateva G. Toward characterization and definition of fibromyalgia severity. BMC Musculoskelet Disord. 2010;11(66):1471-2474.

[13] Assumpcao A, Cavalcante AB, Capela CE, Sauer JF, Chalot SD, Pereira CA, et al. Prevalence of fibromyalgia in a low socioeconomic status population. BMC Musculoskelet Disord. 2009;10(64):1471-2474.

[14] Martinsen S, Flodin P, Berrebi J, Lofgren M, Bileviciute-Ljungar I, Ingvar $\mathrm{M}$, et al. Fibromyalgia patients had normal distraction related pain inhibition but cognitive impairment reflected in caudate nucleus and hippocampus during the Stroop Color Word Test. PLoS One. 2014;9(9):e108637. Epub 2014/10/03.

[15] Verbunt JA, Pernot DH, Smeets RJ. Disability and quality of life in patients with fibromyalgia. Health Qual Life Outcomes. 2008;6(8):1477-7525.

[16] Consoli G, Marazziti D, Ciapparelli A, Bazzichi L, Massimetti G, Giacomelli C, et al. The impact of mood, anxiety, and sleep disorders on fibromyalgia. Compr Psychiatry. 2012;53(7):962-7.

[17]Beg S, Ahmad A, editors. Relationship Between Anxiety, Depression, Sleep, Fibromyalgia and BMI in Patients with Rheumatic Disease. ARTHRITIS \& RHEUMATOLOGY; 2015: WILEY-BLACKWELL 111 RIVER ST, HOBOKEN 07030-5774, NJ USA.

[18] Menzies V, Lyon DE, Elswick RK, Jr., Montpetit AJ, McCain NL. Psychoneuroimmunological relationships in women with fibromyalgia. Biological research for nursing. 2013;15(2):219-25. Epub 2011/12/17.

[19] Williams DA, Arnold LM. Measures of fibromyalgia: Fibromyalgia Impact Questionnaire (FIQ), Brief Pain Inventory (BPI), Multidimensional Fatigue Inventory (MFI-20), Medical Outcomes Study (MOS) Sleep Scale, and Multiple Ability Self-Report Questionnaire (MASQ). Arthritis Care Res. 2011;63(11):20531. 


\section{International Journal of Science and Research (IJSR) \\ ISSN (Online): 2319-7064}

Index Copernicus Value (2013): 6.14 | Impact Factor (2015): 6.391

[20] Bennett RM, Schein J, Kosinski MR, Hewitt DJ, Jordan DM, Rosenthal NR. Impact of fibromyalgia pain on health-related quality of life before and after treatment with tramadol/acetaminophen. Arthritis Care \& Research. 2005;53(4):519-27.

[21] Arnold LM, Crofford LJ, Mease PJ, Burgess SM, Palmer SC, Abetz L, et al. Patient perspectives on the impact of fibromyalgia. Patient Education and Counseling. 2008;73(1):114-20.

[22] Wolfe F, Walitt BT, Katz RS, Hauser W. Social security work disability and its predictors in patients with fibromyalgia. Arthritis Care Res. 2014;66(9):1354-63.

[23] Kashikar-Zuck S, Cunningham N, Sil S, Bromberg MH, Lynch-Jordan AM, Strotman D, et al. Long-term outcomes of adolescents with juvenile-onset fibromyalgia in early adulthood. Pediatrics. 2014;133(3):2013-220.

[24] Dailey DL, Frey Law LA, Vance CGT, Rakel BA, Merriwether EN, Darghosian L, et al. Perceived function and physical performance are associated with pain and fatigue in women with fibromyalgia. Arthritis Research \& Therapy. 2016;18(1):1-11.

\section{Author Profile}

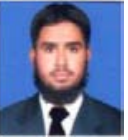

Shahid Ishaq is Doctor of Physical Therapy, Azra Naheed Medical College, Department of Physical Therapy, Main Raiwind Road,, Lahore

Hafiz Sheraz Arshad is Assistant Professor, Azra Naheed Medical College, Department of Physical Therapy, Main Raiwind Road, Lahore

Umer Maqsood is Assistant Professor, Azra Naheed Medical College, Department of Physical Therapy, Main Raiwind Road,, Lahore 